\title{
The Design of the Acoustic Isolator Used in Acoustic Telemetry While Drilling
}

\author{
Xie Haiming ${ }^{1,2^{*}}$, Zhou Jing $^{2}$ and Zhang Feng ${ }^{3}$ \\ ${ }^{I}$ Xidian University, Xian, 710065, P.R. China; ${ }^{2}$ Xian Shiyou University, Xian, 710065, P.R. China; ${ }^{3}$ China Ship Scien- \\ tific Research Center, Xian, 710000, P.R. China
}

\begin{abstract}
The acoustic isolator between the drilling bit and the acoustic piezoelectric transducer can attenuate the drilling noise transmitted through the drill collar to avoid interference with the transmission of acoustic signals while drilling, and also can be used to weaken the influence of downlink acoustic signal with the uplink channel produced by the transducer. This paper improves the characteristic analysis of tapered acoustic transmission model, and the size and structure of the acoustic isolator has been designed which has the characteristic frequencies of $700 \sim 800 \mathrm{~Hz}$ and $1200 \sim 1300 \mathrm{~Hz}$.
\end{abstract}

Keywords: Acoustic isolator, Acoustic telemetry while drilling, Acoustic transmission, Modeling analysis.

\section{INTRODUCTION}

The wireless Measurement While Drilling system (MWD) is widely used in the field of drilling, can real-time detect and upload the formation parameters and borehole attitude parameters in the drilling process to ensure that the borehole trajectory is drilling in accordance with the requirements. The transmission medium of MWD can be mud pulse and electromagnetic waves, acoustic and optical fiber etc. The MWD of mud pulse or electromagnetic waves has been widely used in oilfield. Affected by the drilling fluid, the method of mud pulse MWD cannot be used in air drilling or foam drilling, and the transmission capacity is limited. The domestic instrument's transmission rate can only reach 3$5 \mathrm{bps}$, but it can reach 10bps in other countries. The method of electromagnetic waves MWD cannot be used in the low resistivity formation, and the transmission distance is limited, which can not be applied to the deep well operation [14].

The acoustic telemetry while drilling technique uses elastic waves for data transmission in the drill column, cannot be influenced by drilling fluid and formation resistivity. With the influence of drill string's cycle section and drilling noise, the theoretical rate of acoustic transmission can reach 100bps [1]. In 2007, XACT downhole telemetry company published the transmission rate of downhole acoustic transmission system to $20 \mathrm{bps}$, and the test well depth is $2500 \mathrm{~m}[5,6]$.

Compared with the acoustic information transmission system used in production wells, the entire system is the first to be affected by the noise in the process of drilling and the wave reflected by the drill assembly under the telemetry system. These kinds of noise are transmitted into the acoustic transmission channel, which causes interference with the

*Address correspondence to this author at the Xidian University, Xian, Shaanxi, 710065, P.R. China; Tel: +86 29 88382636; Fax: +86 29 88382636; E-mail: haimingxie@xsyu.edu.cn acoustic telemetry signal. The downhole BHA cannot be designed according to the characteristics of acoustic telemetry transmission system. Therefore the acoustic isolator must be designed to eliminate acoustic reflection noise [1].

The acoustic telemetry instruments while drilling are mainly composed of acoustic transmitting transducer, receiving transducer, acoustic isolator and the supporting electronic circuit components. The Acoustic signals generated by acoustic transmitting transducer propagates upward along the drill pipe to the surface, and a reflection signal is generated when the acoustic signal propagates down to the downhole drill assembly, which interferes with the uplink signal seriously.

The acoustic isolator is positioned between the drilling bit and the transmitting transducer. The acoustic isolator has two major functions: attenuating the drilling noise through the acoustic isolator above the drilling bit to avoid the noise signal propagating along the drill collar and affecting the acoustic signal telemetry; weakening the influence of the reflection signal produced by transmitting transducer for the uplink channel.

In the acoustic telemetry signal transmission process while drilling, the noise generated by the drill bit is mainly in the frequency band range below $600 \mathrm{~Hz}$. The transmitting band of signal is selected from $700 \mathrm{~Hz}$ to $2000 \mathrm{~Hz}$ [7-10]. This paper mainly completes the design of acoustic isolator with transmission channel frequency of $700 \sim 800 \mathrm{~Hz}$ and $1200 \sim 1300 \mathrm{~Hz}$ interval.

\section{THE CREATION OF A TRANSMISSION MODE}

The calculation methods for acoustic transmission in the periodic drill pipe mainly include Douglas finite difference method and the equivalent transmission film method [11]. The former can only calculate the acoustic transmission characteristics of periodic drill pipe with two kinds of cross 
section, the latter can also calculate the sound transmission characteristics of various cylindrical section combined pipe structure, but not for the tapered section rod and various special-shaped rods. The design of an acoustic isolator is mainly dependent on finite element software and the test of model after machining. There is no fast estimation method that can be used in practical engineering [12-20].

According to the characteristics of the structure design of the acoustic isolator, the four-pole network parameter transfer matrix for the vibration of different cross section cylindrical bars or tapered bars, is obtained based on the structure longitudinal vibration theory. The vibration transmission characteristics of the acoustic isolator with arbitrary cross section combined structures has been got under certain boundary conditions. According to the input and transfer impedance of the acoustic isolator, the relationship between the vibration speed and the force of the input and output at the two ends of the acoustic isolator has been obtained. Thus the model design method of the acoustic isolator engineering calculation has been completed.

\subsection{The Establishment of Various Tapered Cylindrical Pipe Vibration Equation and the Four End Parameter Equation}

1. The vibration equation of linear tapered cross section pipe

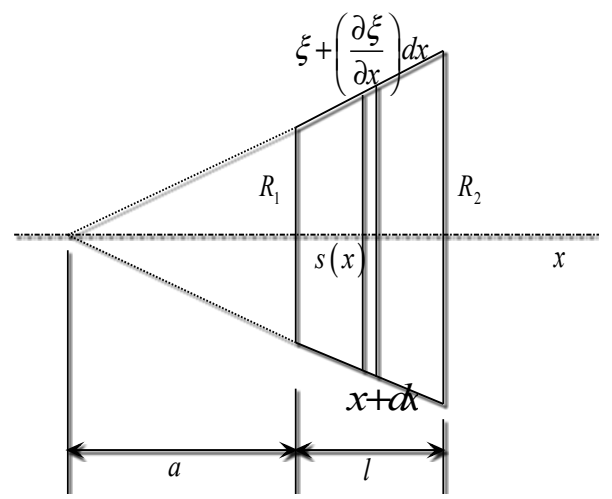

Fig. (1). Linear tapered cross section pipe vibration displacement relationship.

The vibration displacement relationship of variable crosssection cylindrical rod is shown in Fig.(1). The following assumptions are made:

- All particles in the rod only have the axial displacement, and each particle is only the function of coordinates and time;

- The strain in the pipe is uniformly distributed over the entire cross section, and the cross section has no bending deformation;

- If the longitudinal stress is applied to the section position $x$, it's displacement is $\xi$, then the displacement at the position of $x+d x$ is $\xi+d \xi$, which $d \xi$ is the incremental displacement;

The strain and stress in the pipe:

- The strain rate is the ratio of unit length displacement increment and unit length, $\sigma=\left(\frac{\partial \xi}{\partial x}\right) d x / d x=\frac{\partial \xi}{\partial x}$

- The longitudinal stress $T$ is the compression force on the per unit area of the cross section

$T=\frac{F}{s(x)}$,

and $s(x)$ is the cross-sectional area of the pipe at position $x$.

Among them: $c^{2}=Y / \rho$ is the longitudinal wave velocity in the material.

Considering the simple harmonic vibration of the structure $\xi=\xi e^{j \omega t}$, Then it can be obtained:

$\frac{\partial^{2} \xi}{\partial x^{2}}+\frac{1}{s(x)} \frac{\partial s(x)}{\partial x} \frac{\partial \xi}{\partial x}+k^{2} \xi=0$

Among them: $k=\omega / c$ is the longitudinal wave number. The equation (1) is the displacement equation of one dimensional longitudinal vibration of the variable section bar.

The velocity of the simple harmonic vibration can be written in the form of

$$
v=\frac{\partial \xi}{\partial t}=j \omega \xi e^{j \omega t} \text {. }
$$

If the vibration displacement in the pipe is the independent variable of axis $x$ and time $t$, the equation (1) can be written in the form of differential equations of particle vibration velocity:

$\frac{\partial^{2} v}{\partial x^{2}}+\frac{1}{s(x)} \frac{\partial s(x)}{\partial x} \frac{\partial v}{\partial x}+k^{2} v=0$

The transfer force of the pipe is:

$F=Y_{S}(x) \frac{\partial \xi}{\partial x}=-j \frac{Y_{S}(x)}{\omega} \frac{\partial v}{\partial x}$

2) Solving the equation is divided into two types: 1 . uniform cross-section cylindrical pipe; 2.variable cross-section uniform cylindrical pipe.

(1) Uniform cylindrical pipe with equal section

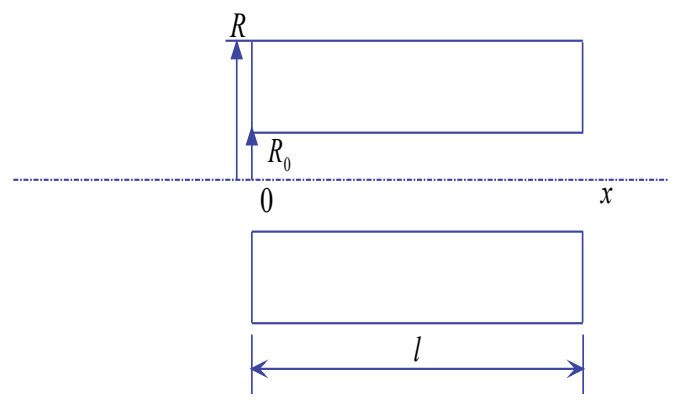

Fig. (2). Uniform cylindrical pipe of equal section.

As shown in Fig. (2), if $z=\rho c s_{0}$, the above equations can be solved to get the relationship between input and output, which can be written in the form of the four-pole parameters matrix: 
$\left[\begin{array}{l}v_{1} \\ F_{1}\end{array}\right]=\left[\begin{array}{cc}\cos k l & \frac{1}{j z} \sin k l \\ -j z \sin k l & \cos k l\end{array}\right]\left[\begin{array}{l}v_{2} \\ F_{2}\end{array}\right]$

The elements in the matrix formula (4) are four-pole parameters for uniform cylindrical pipe vibration. They describe the relationship between the vibration transfer velocity and the elastic force of the input and output at both ends of a cylindrical rod.

(2) Variable cross-section uniform cylindrical pipe

If the pipe is a variable cross-section column, the cross sectional area $s(x)$ is a function of position coordinates, then solving the equation is more complex. Then the vibration equations of several variable cross-section cylindrical bars can be solved to get the four-pole parameters equations.

1. Linear tapered cross section pipe

As shown in Fig. (1), the cross-sectional area of a linear tapered cross section pipe can be expressed as shown below:

$s(x)=\pi r^{2}(x)=\pi\left[\frac{R_{2}-R_{1}}{l} x+R_{1}\right]^{2}$

The relation between input and output can be obtained by solving the above equations (3) and (5):

$v_{1}=\alpha_{11} v_{2}+\alpha_{12} F_{2}$

$F_{1}=\alpha_{21} v_{2}+\alpha_{22} F_{2}$

Among them:

$\alpha_{11}=\frac{f_{2}^{\prime} g_{1}-g_{2}^{\prime} f_{1}}{f_{2}^{\prime} g_{2}-g_{2}^{\prime} f_{2}}$

$\alpha_{12}=\frac{1}{j z_{2}} \frac{f_{1} g_{2}-g_{1} f_{2}}{f_{2}^{\prime} g_{2}-g_{2}^{\prime} f_{2}}$

$\alpha_{21}=j z_{1} \frac{f_{2}^{\prime} g_{1}^{\prime}-f_{1}^{\prime} g_{2}^{\prime}}{f_{2}^{\prime} g_{2}-g_{2}^{\prime} f_{2}}$

$\alpha_{22}=\frac{z_{1}}{z_{2}} \frac{f_{1}^{\prime} g_{2}-g_{1}^{\prime} f_{2}}{f_{2}^{\prime} g_{2}-g_{2}^{\prime} f_{2}}$

The four-pole network parameters relation of a tapered rod is written as a matrix form:

$\left[\begin{array}{l}v_{1} \\ F_{1}\end{array}\right]=\left[\begin{array}{ll}\alpha_{11} & \alpha_{12} \\ \alpha_{21} & \alpha_{22}\end{array}\right]\left[\begin{array}{l}v_{2} \\ F_{2}\end{array}\right]$

2. The equal wall thickness hollow tapered pipe

At each end of the drilling pipe, there is a wall thick hollow tapered rod with a thread, as shown in Fig. (3).

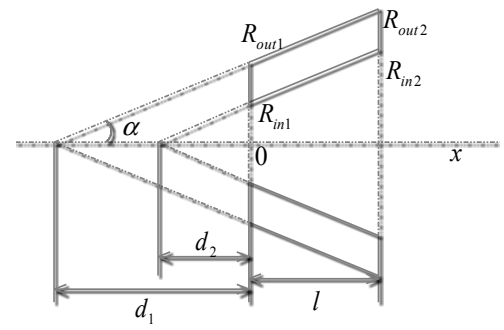

Fig. (3). The equal wall thickness hollow tapered pipe.
Through the solution, the following four-pole parameters matrix formula can be obtained:

$\left[\begin{array}{l}v_{1} \\ F_{1}\end{array}\right]=\left[\begin{array}{ll}\beta_{11} & \beta_{12} \\ \beta_{21} & \beta_{22}\end{array}\right]\left[\begin{array}{l}v_{2} \\ F_{2}\end{array}\right]$

Among them:

$\beta_{11}=\frac{g_{2}^{\prime} f_{1}-f_{2}^{\prime} g_{1}}{f_{2} g_{2}^{\prime}-f_{2}^{\prime} g_{2}}$

$\beta_{12}=\frac{1}{j z_{2}} \frac{f_{2} g_{1}-f_{1} g_{2}}{f_{2} g_{2}^{\prime}-f_{2}^{\prime} g_{2}}$

$\beta_{21}=j z_{1} \frac{g_{2}^{\prime} f_{1}^{\prime}-f_{2}^{\prime} g_{1}^{\prime}}{f_{2} g_{2}^{\prime}-f_{2}^{\prime} g_{2}}$

$\beta_{22}=\frac{z_{1}}{z_{2}} \frac{f_{2} g_{1}^{\prime}-g_{2} f_{1}^{\prime}}{f_{2} g_{2}^{\prime}-f_{2}^{\prime} g_{2}}$

3. The hollow straight tapered pipe
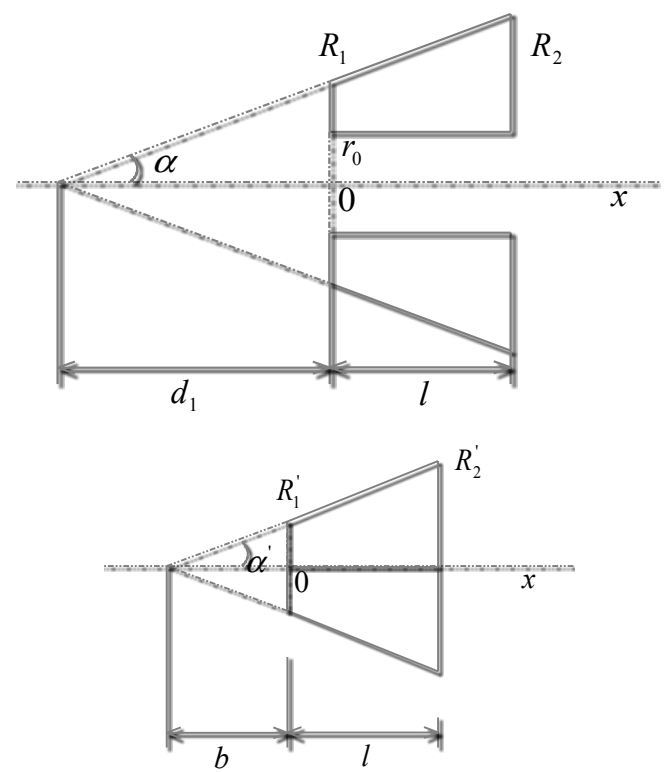

Fig. (4). The hollow straight tapered pipe.

As shown in Fig. (4), the expression of the solution is the same as of the Linear straight tapered pipe. Assuming $x=0$ or $x=l$ respectively, the expressions of velocity and elastic force at both ends of the rod are obtained. After simplification, the four-pole parameters matrix equation of the hollow straight tapered pipe can be obtained:

$\left[\begin{array}{l}v_{1} \\ F_{1}\end{array}\right]=\left[\begin{array}{ll}\gamma_{11} & \gamma_{12} \\ \gamma_{21} & \gamma_{22}\end{array}\right]\left[\begin{array}{l}v_{2} \\ F_{2}\end{array}\right]$

Among them, the four-pole parameters $\gamma_{11}, \gamma_{12}, \gamma_{21}, \gamma_{22}$ are the same as of the parameters $\alpha_{11}, \alpha_{12}, \alpha_{21}, \alpha_{22}$ of the linear tapered pipes, but the height of the conical tip is changed from $a$ to $b$.

With tapered bore cylindrical pipe 


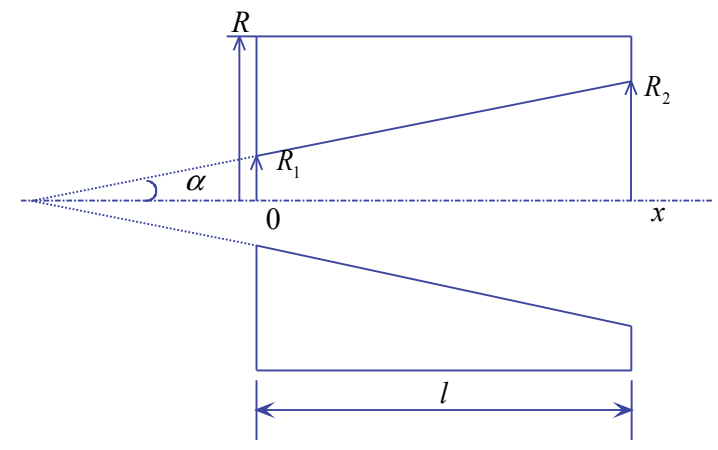

Fig. (5). With tapered bore cylindrical pipe.

The female thread connecting the drill pipes is usually a straight cylindrical rod with a conical hole. The structure profile is shown in Fig. (5), the radius of the outer cylindrical pipe is $R$, the small end radius of the inside hollow conical pipe is $R_{1}$, the other end radius is $R_{2}$, the length is $l$.

The four-pole parameters matrix structure of input and output can be got:

$\left[\begin{array}{l}v_{1} \\ F_{1}\end{array}\right]=\left[\begin{array}{ll}\chi_{11} & \chi_{12} \\ \chi_{21} & \chi_{22}\end{array}\right]\left[\begin{array}{l}v_{2} \\ F_{2}\end{array}\right]$

among them:

$\chi_{11}=\frac{-f_{2}}{g_{2}\left(R-R_{1}\right)\left(f_{1} \sin k l-f_{2} \cos k l\right)}$

$\chi_{12}=\frac{g_{2} \sin k l}{g_{3}\left(R-R_{1}\right)}$

$\chi_{21}=\left(\frac{z_{2}}{k}\right)^{2} \frac{R_{1} D f_{2}-k\left(R-R_{1}\right) f_{1}}{g_{3}\left(R-R_{1}\right)^{2}}$

$\chi_{22}=\frac{j z_{1}}{k} g_{2} \frac{R_{1} D \sin k l+k\left(R-R_{1}\right) \cos k l}{g_{3}\left(R-R_{1}\right)^{2}}$

$f_{1}=g_{1} \cos k l+g_{2} k \sin k l$

$f_{2}=g_{1} \sin k l-g_{2} k \cos k l$

$g_{3}=\frac{j z_{2}}{k} g_{2}\left(f_{1} \sin k l-f_{2} \cos k l\right)$

\subsection{The Four-Pole Parameters of the Tapered Pipe with a Reverse Structure}

When the structure is positively excited, the calculation methods of four-pole parameters of the longitudinal vibration transmission characteristics have been given in the above sections. But in fact, the structure can be also subjected to reverse impact excitation or placed in the opposite direction under the reverse excitation, so that the inverse matrix of the four end parameter matrix of the structure needs to be solved. Then the inverse four-pole parameters matrix of the structure can be obtained.

The matrix of the four-pole parameters of the forward transfer of the structure is as follows:

$$
\left[\begin{array}{l}
v_{1} \\
F_{1}
\end{array}\right]=\left[\begin{array}{ll}
a_{11} & a_{12} \\
a_{21} & a_{22}
\end{array}\right]\left[\begin{array}{l}
v_{2} \\
F_{2}
\end{array}\right]
$$

If the structure is under reverse incentives, the matrix of the four-pole parameters can be written as follows:

$\left[\begin{array}{l}v_{2} \\ F_{2}\end{array}\right]=\left[\begin{array}{ll}b_{11} & b_{12} \\ b_{21} & b_{22}\end{array}\right]\left[\begin{array}{l}v_{1} \\ F_{1}\end{array}\right]$

The two transfer matrices satisfy the following relation:

$\left[\begin{array}{ll}b_{11} & b_{12} \\ b_{21} & b_{22}\end{array}\right]=\left[\begin{array}{ll}a_{11} & a_{12} \\ a_{21} & a_{22}\end{array}\right]^{-1}$

\section{THE DESIGN OF THE ACOUSTIC ISOLATOR}

\subsection{The Design of the Variable Cross Section Acoustic Isolator}

According to the standard of drill pipe, Fig. (6) illustrates the structure of the acoustic isolator which has been designed. The output end of the structure is on the left, while the input end is on the right. At both ends of acoustic isolator is the NC50 standard thread joint. The length of each side is different. The length of the left joint structure is $254 \mathrm{~mm}$, the radius is $89 \mathrm{~mm}$, and the length of the right joint structure is $292.1 \mathrm{~mm}$, and the radius is $89 \mathrm{~mm}$. The hollow straight cone pipe is used to connect the joint structure with the central cylindrical pipe. The length of the left straight cone pipe is $80 \mathrm{~mm}$, and the length of the left straight cone pipe is $70 \mathrm{~mm}$. The length of the middle small section cylinder pipe is $3245.4 \mathrm{~mm}$ and the section radius is $63.5 \mathrm{~mm}$. The length of the larger section of cylinder pipe is $1500 \mathrm{~mm}$, whereas the section radius is $89 \mathrm{~mm}$. The whole length of the acoustic isolator is $8686.8 \mathrm{~mm}$, and the maximum section radius is $89 \mathrm{~mm}$.

The acoustic isolator body is divided into 7 sections of hollow cylindrical rod and conical rod with different cross sections to be simulated. Based on the structural vibration theory, the vibration transmission characteristics of the structure are obtained by putting the structure parameters of each section into the calculation program. The results are shown in Figs. $(7,8)$. The combined structure of the threaded joints of two drill rods is a cylindrical structure with equal cross section. Therefore, the NC50 threaded joint can be considered as an equal section cylinder for simulation.

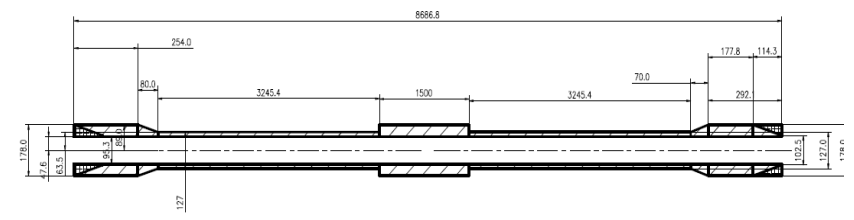

Fig. (6). The design of cylindrical pipes combining acoustic isolator.

Fig. (7) illustrates the transfer coefficient of the velocity and excitation force of an acoustic isolator under different boundary conditions. From the calculated values of the ordinates, the maximum value is $9.85 \mathrm{e} 3$, the minimum value is 0.177 , the variation range is between 0.1 and 10000 , and it is over 5 orders of magnitude. The phenomenon of enlargement is obvious, and there is obvious phenomenon of signal 
amplification. Fig. (8) shows the velocity admittance curve of the structure's input force under the free boundary condition, and it is always the speed response of the output end with the input force of $1 \mathrm{~N}$. The maximum velocity occurs at the $302 \mathrm{~Hz}$, the value is $0.053 \mathrm{~m} / \mathrm{s}$. The corresponding frequency points of the other peak vibration points are: $451 \mathrm{~Hz}$ , $923 \mathrm{~Hz}, 1051 \mathrm{~Hz}, 1505 \mathrm{~Hz}, 1735 \mathrm{~Hz}, 1974 \mathrm{~Hz}, 2439 \mathrm{~Hz}$ etc.

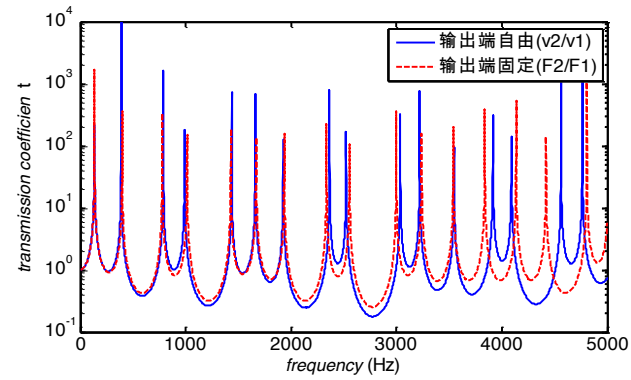

Fig. (7). The transfer coefficient with the output end free and fixed boundary conditions.

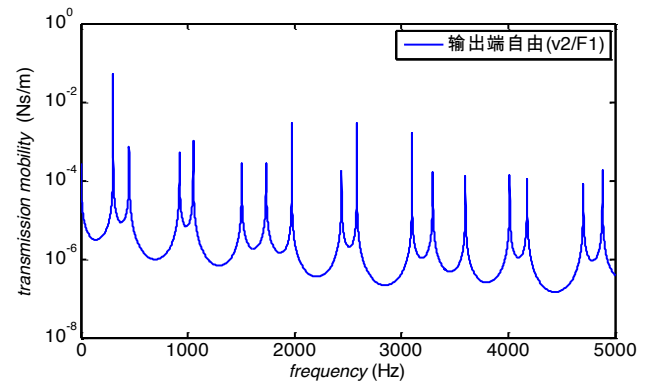

Fig. (8). The transfer admittance curve with the condition of the output end free.

Fig. (9) shows the structure transfer admittance curve with the frequency band of $500-1500 \mathrm{~Hz}$. The stop bands of the acoustic isolator are designed in $700-800 \mathrm{~Hz}$ and $1200-$ $1300 \mathrm{~Hz}$. As shown in Fig. (9), there is no resonance peak in the two frequency bands. The values of the transfer admittance are reduced to $0.3 \%$ and $0.09 \%$ of the resonance peak, that is compared with resonance peaks of $923 \mathrm{~Hz}$ and $1051 \mathrm{~Hz}$, which are reduced by $49.7 \mathrm{~dB}$ and $61.2 \mathrm{~dB}$.

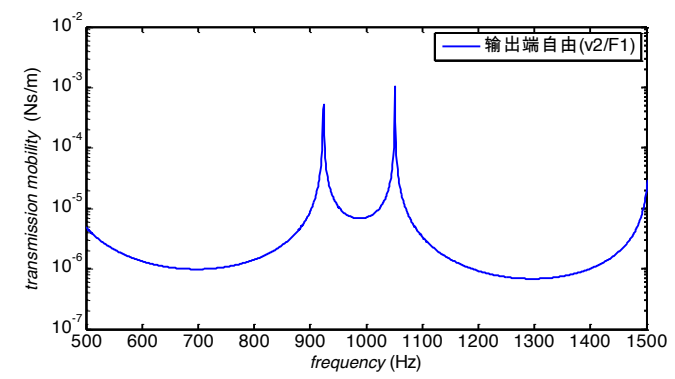

Fig. (9). The structural transfer admittance curve of the 500-1500 frequency band.

\subsection{The Finite Element Simulation of the Variable Cross- section Acoustic Isolator}

In order to verify the design, the finite element software ANSYS is used to simulate the design model as shown in
Fig. (10). Through calculation, the natural frequency of the structure is obtained as shown in Table 1, the natural mode of the structure is obtained as shown in Fig. (11), and the transfer response curve of the structure under the excitation of the unit force is also presented.

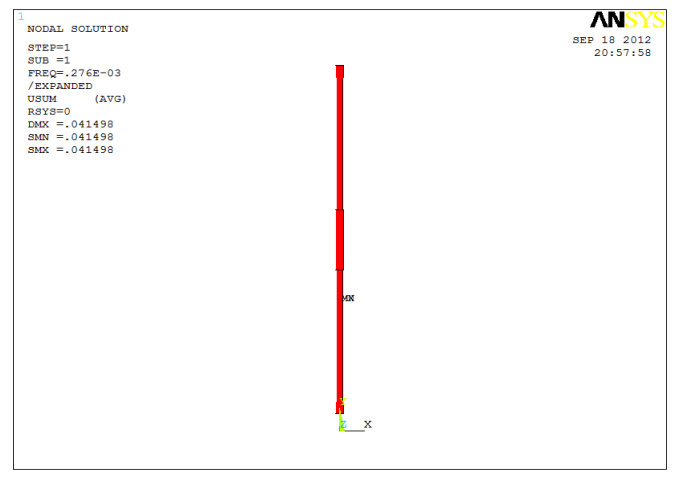

Fig. (10). The finite element model of the acoustic isolator.

Table 1. The natural frequency of the acoustic isolator's first 8 orders.

\begin{tabular}{|c|c|c|c|}
\hline Order & $\begin{array}{c}\text { Simulation } \\
\text { value }\end{array}$ & $\begin{array}{c}\text { Theoretical } \\
\text { value }\end{array}$ & Error \% \\
\hline \hline 1 & 292.30 & 302 & 3.2 \\
\hline 2 & 439.69 & 451 & 2.5 \\
\hline 3 & 902.98 & 923 & 2.1 \\
\hline 4 & 1025.9 & 1051 & 2.3 \\
\hline 5 & 1485.8 & 1505 & 1.2 \\
\hline 6 & 1701.4 & 1735 & 1.9 \\
\hline 7 & 1950.5 & 1974 & 1.1 \\
\hline 8 & 2402.3 & 2439 & 1.5 \\
\hline
\end{tabular}

In Table 1, the error of the natural frequency between the calculated results and the theoretical analysis is not more than $3.2 \%$, and the minimum difference between the frequencies is $10 \mathrm{~Hz}$. From the natural modal analysis of the structure, it can be seen that the vibration displacement at both ends of the acoustic isolator is the largest at the resonance frequency.

The unit excitation force is applied to the upper end of the acoustic isolator to calculate the vibration transmission characteristics of structure under free boundary condition, to acquire the node vibration velocity of the acoustic isolator's lower end. The result of finite element simulation of structural transfer admittance is compared with that of theoretical calculation, as shown in Fig. (12). The differences between the calculation results of the structural transfer admittance's finite element simulation are compared with the results of theoretical calculations, as shown in Fig. (12).

The peak frequency of finite element calculation is consistent with the theoretical calculation results before $3000 \mathrm{~Hz}$. 

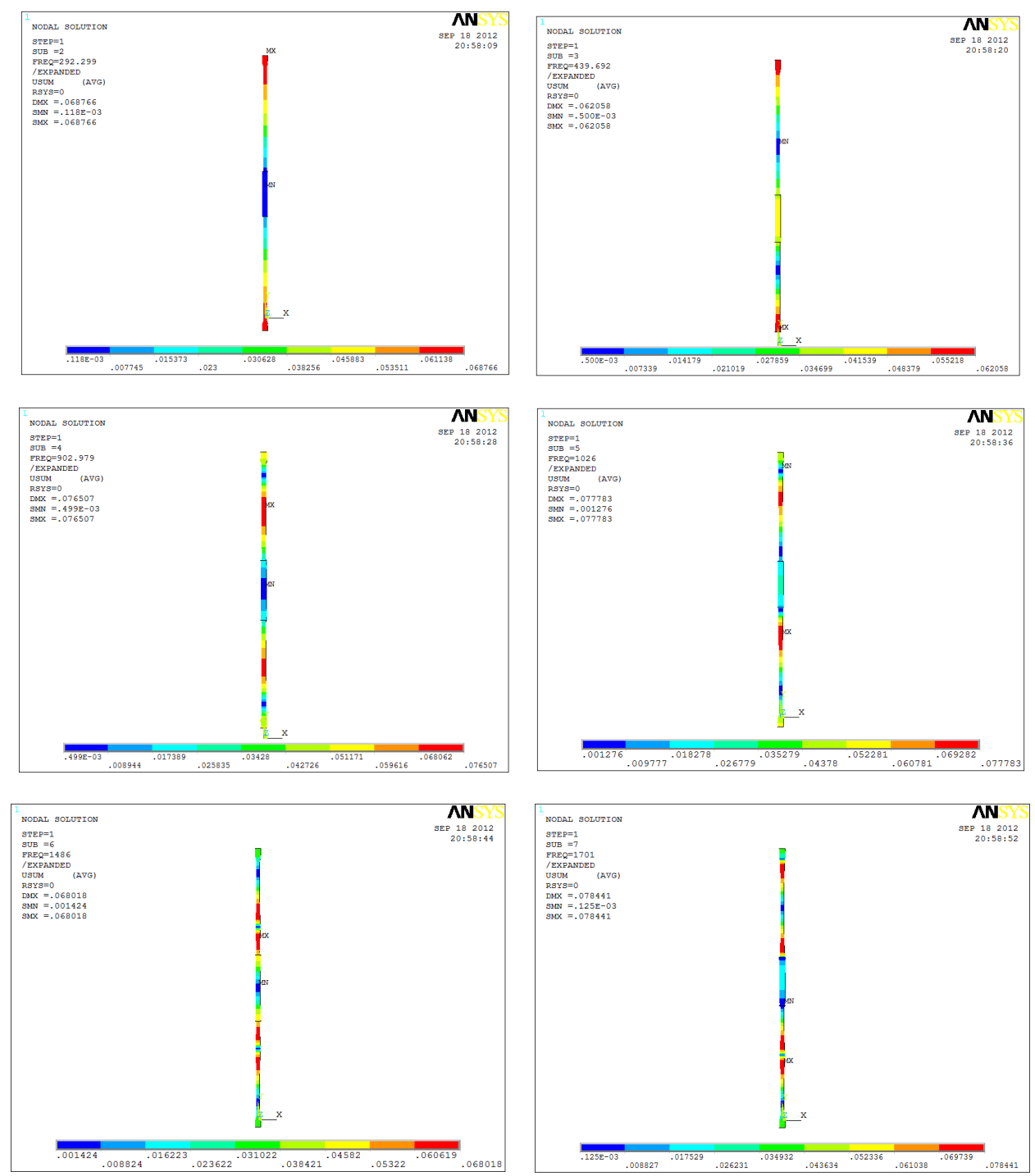

Fig. (11). The natural mode of the acoustic isolator's first six order modes.

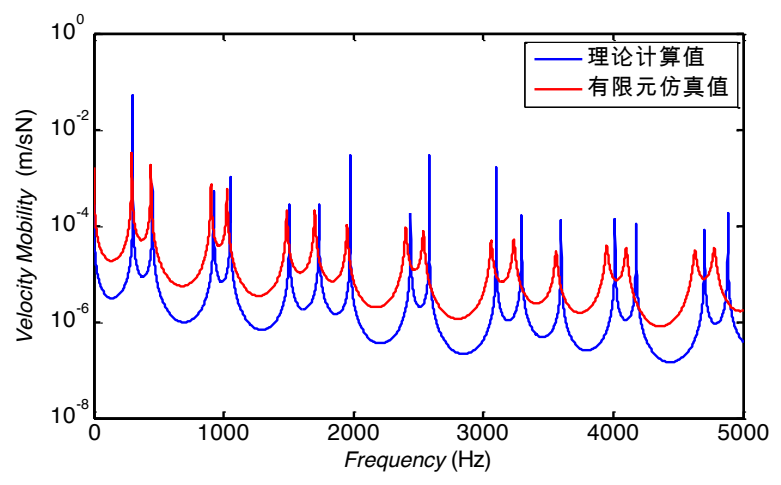

Fig. (12). The comparison of theoretical calculation with finite element simulation of the acoustic isolator's speed transfer admittance.

The damping factor is considered in the finite element harmonic response analysis, but the structural damping is not considered in the theoretical calculation. Therefore, the calculated value of the finite element is slightly smaller than the theoretical value on the peak value.
The pass band and stop band of the finite element calculation frequency are fully consistent with the theoretical calculation values, which also proves the reliability of this calculation method again.

\section{CONCLUSION}

Through the analysis of the longitudinal vibration transfer relationship of a variable cross-section cylindrical rod, the expressions of longitudinal vibration speed and force acting on input and output terminals of the variable crosssection cylindrical or conical rods are obtained, the four-pole parameters characterization method for acoustic vibration transmission of drill string is established. Through comparison, it is shown that the defined transfer admittance parameter can reflect the vibration transfer characteristics of combined drill string structure. By comparison, it can be shown that the defined parameters of transfer admittance can reflect the vibration transmission characteristics of the combined drill string structure. Based on this method, the structure of acoustic isolator composed of variable cross-section cylindrical rods is designed, the theoretical calculation of which is 
consistent with the finite element simulation results. The transmission characteristics of the acoustic isolator body meet the design requirements of the sound attenuation of $50 \mathrm{~dB}$ in the $700-800 \mathrm{~Hz}$ or the $1200-1300 \mathrm{~Hz}$ bands.

\section{CONFLICT OF INTEREST}

The authors confirm that this article content has no conflict of interest.

\section{ACKNOWLEDGEMENTS}

Declared none.

\section{REFERENCES}

[1] L. Chao, "The Research and Development of MWD Data Acoustic Transmission Technology Based on Drill Pipe", PhD thesis, China University of Petroleum, 2010.

[2] C. Litian, "The Research of Acoustic Sending and Receiving Electronic System Along Drill Strings", PhD thesis, China University of Petroleum, 2011.

[3] M. Zhe, Y. Jinzhou, and Z. Jinhai, "The application situation and development trend of wireless MWD Technology", Petroleum Drilling Techniques, vol. 35, no. 6, pp. 112-115, 2007.

[4] T. Bing, "MWD Mud Pulse Signal Identification and Ground Adaptation Technology Research", $\mathrm{PhD}$ thesis, Beijing University of Technology, 2013.

[5] L. Cheng, J. Zhongwu, and L. Zhao, "Modeling and simulation analysis for an acoustic isolation structure in a drillstring channel", Journal of Vibration and Shock, vol. 32, no. 22, pp. 53-56, 67, 2013.

[6] D. Zhifeng, "The Structure Design of MWD Acoustic Telemetry System of Oil and Gas Wells", PhD thesis, China University of Petroleum, 2011.

[7] T. Xiaoming, S. Yuanda, and T. Baohai, "Drill-following Acoustic Logging Method and Device Capable of Reducing and Insulating
Sound on Drill Collar", China, CN201110299591.3[P]. 2013-1030.

[8] S. Xue, "Research on Measurement and Analysis of Drillstring Vibration", PhD thesis, China University of Petroleum, 2010.

[9] Y. Wei, Signal Detection of the Drill Bit Seismic Wave While Drilling, Institute of Geophysics, China Earthquake Administration, 2007.

[10] Z. Xueqin, The Dynamics Analysis of Rod String in Screw Pump Well end Research Eccentric Wear Prevention Methods, Daqing Petroleum Institute, 2010.

[11] D. S. Drumheller, "Acoustical properties of drill strings", Journal of Acoustical Society of America, vol. 85, no. 3, pp. 1048-1064, 1989.

[12] L. Cremer, Structure-Borne Sound, Springer-Verlag Berlin Heidelberg, 2005.

[13] F. Fahy, Sound and Structural Vibration, Elsevier, 2007.

[14] N. Jianhua, "Research on Piezoelectric Transducer Consistency Screening Technology and Sound Isolator Design Technique", PhD thesis, Tianjin University, 2009.

[15] Y. Xianghong, S Yuanda, and S. Jianmeng, "Acoustic characteristics of axisymmetric periodic groove structures", Chinese Journal of Computational Physics, vol. 27, no. 6, pp. 82-89, 2010.

[16] Z. Chunxi, "Numerical Simulation and Experiments on Isolator Logging-While-Drilling (LWD) Acoustic Tool", $\mathrm{PhD}$ thesis, China University of Petroleum, 2011

[17] Z. Meiling, "Numerical Simulation Investigation on Sound Isolator of Acoustic Logging While Drilling", PhD thesis, China University of Petroleum, 2011.

[18] S. Yuanda, Z. Chunxi, D. Line, L. Yuxia, and Q. Yukun, "Experimental Research on Performance Evaluation of LWD Acoustic Isolator", Well Logging Technology, vol. 35, no. 5, pp. 402-405, 2011.

[19] W. Guoping, "Patent analysis for the acoustic logging while drilling technology", Petroleum Instruments, vol. 24, no. 3, pp. 1-3, 2010.

[20] L. Bin, W. Fang, C. Dehua, and C. Chengxuan, "Numerical simulation on acoustic insulation performance of a periodic nonaxisymmetry groove structure", Applied Acoustics, vol. 31, no. 5, pp. 333338,2012 .

(C) Haiming et al.; Licensee Bentham Open.

This is an open access article licensed under the terms of the (https://creativecommons.org/licenses/by/4.0/legalcode), which permits unrestricted, noncommercial use, distribution and reproduction in any medium, provided the work is properly cited. 